\title{
The Effects of Theatrical Play Intervention Using Psychoanalytic Theories: A Research Analysis on Children with Anxiety Symptoms
}

\author{
Pilios-Dimitris Stavrou* \\ ${ }^{1}$ Department of Psychology, University of Athens, Athens, Greece, 10679 \\ ${ }^{2}$ Laboratory of Clinical Psychology, Psychopathology and Psychoanalysis (PCPP), \\ University Paris Descartes - Sorbonne, Paris, France \\ *Corresponding author: pstavrou@otenet.gr, pilios.stavrou@gmail.com
}

\begin{abstract}
The present research aimed to investigate the effectiveness of psychodynamic theatrical play on children with symptoms of anxiety. Drawing from psychoanalytic theories concerning object relations, symbolic function and transitional space, the paper discusses the different dynamics employed during twelve sessions of theatrical play, as well as the procedural progress of the children who participated in the process. The theoretical implications of the theories of Vygotsky, Klein, Piaget and Anzieu are contextualised in this research analysis, which used a kinetic family drawing and a draw-a-person test to establish the anxiety symptoms and emotional stability of three children aged 10 to 12 before and after the completion of twelve sessions of theatrical play, in order to examine the potential effectiveness of an intervention based on the above principles. The different phases of the intervention are analysed and the outcomes of the intervention are discussed.
\end{abstract}

Keywords: theatrical play, psychoanalytic theories, symbolic function, symbolization, object relations, intervention

Cite This Article: Pilios-Dimitris Stavrou, "The Effects of Theatrical Play Intervention Using Psychoanalytic Theories: A Research Analysis on Children with Anxiety Symptoms." American Journal of Educational Research, vol. 6, no. 7 (2018): 988-996. doi: 10.12691/education-6-7-15.

\section{Introduction}

There is a wide variety of research conducted in the field of art therapy and the benefits it holds for neurotypical as well as neuroatypical children [1]. The different types of art therapy, including music therapy, drama, theatrical play and play based interventions have been employed on children suffering from developmental difficulties, autistic children, children facing social communication deficits and children with attachment issues. An art based therapeutic intervention that has been proved extremely lucrative on children is that of theatrical play. In the present article, the focus is on theatrical play, employed using psychoanalytic theories, and the effects in holds for neurotypical children suffering from anxiety symptoms. In detail, we conducted a research on three children aged 10 to 12 who were referred to out practice due to anxiety symptoms. As their age and symptoms were similar, we decided to form a theatrical play group based on psychoanalytic principles and conducted twelve theatrical play sessions over the course of six months, in which the researcher formulated an unstructured dramatization process based on psychoanalytic principles, and the progress of the children who participated was documented by the researcher using observational notes. The content of the sessions was based on concepts of psychoanalytic theorists who incorporated notions such as symbolic function, symbolization, mentalization, transitional space and object relations in their work.

Indeed, a psychoanalytic approach to theatrical play requires the utilization of certain notions that define the field and shape the psychoanalytic school of thought. The first notion under consideration is object relations, a term introduced by Freud and widely used by Melanie Klein. According to psychoanalysts who subscribe to an object relations approach to treatment, humans have an innate drive to form and maintain relationships and it is through our relationships with people around us that our personality is shaped. At later stages of development, personality can be altered, but it is common for humans to seek out others who will reaffirm these early relationships. These early relationships that define so greatly one's personality and shape one's future social interactions, both in reality and in fantasy are called object relations [2]. This theory provides a framework that allows a deeper understanding of ways individuals superimpose early relationships and experiences on present relationships.

Clearly, the term "object" is at the central to the theory of object relations. Freud suggested that an object in this case can be a person, thing, or mental representation through which one is gratified, whereas Melanie Klein [3] explained that the object refers to someone (usually the mother) onto whom the child projects desires, wishes, or other powerful emotions. Therefore, it can be easily assumed that the concept of attachment lays at the foundation of object relations. Initially, a child is joined 
with mother, experiencing bonding along with good and bad aspects of that attachment; the task is to successfully separate from mother and eventually, with maturity, to take in all aspects, both good and bad, and develop autonomy.

In the field of art therapy, the concept of object relations was successfully introduced by Robbins [4,5], who worked with adults with psychiatric problems and observed that art of any form can contain, organize, and mirror internal object relations and the interplay between therapist, client, and art product. The observation and facilitation of art expression in a therapeutic context helps to amplify unresolved interpersonal issues that may need to be resolved for the improvement of one's emotional well-being. Henley [6,7], who has applied an object relations approach to his work with children with developmental and emotional disabilities, has noted that individuals with disabilities can be benefited from art therapy, as it aids them in the development of the reconstruction of early attachment bonds, which can be impaired or underdeveloped. Since the introduction of object relations facilitates the sequence of attachment, the art process which is based on these principles encourages sensory stimulation, object formation, and interaction with both therapist and the art product. In other words, art therapy in its many forms can add a different dimension to the therapeutic relationship, since it allows for the processes of individuation and separation to be witnessed, practiced, and mastered through creative exploration.

Moving further into psychoanalytic concepts directly related to art therapy, two concepts in object relations theory that are of particular interest to art therapy are Winnicott's [8] concepts of "transitional space" and "transitional objects." According to Winnicott, transitional space is defined as an intermediate area of experience where there is no clear distinction between inner and outer reality. Based on the above, it can be understood that art making and play activities can be considered transitional spaces since they function as ways for children to bridge subjective and objective realities and practice relating to others around them. Thus, a therapeutic setting where the therapist provides art supplies and facilitates creative expression, can be experienced as a holding environment within which object relations can develop. In line with the above, "transitional object" is defined by Winnicott as an actual object, such as a blanket or a toy which represents something different than what it is. In an art therapy framework, art products can become transitional objects, and their use may diffuse or symbolically diffuse unresolved issues [8].

Art therapy also favours psychoanalytic work with defence mechanisms. These mechanisms must be respected because they could be the only way available for the patient to cope with their difficulties. They are what the art therapist will rely on to carry out their work. The therapist must first build their therapeutic approach taking into account what is repressed, avoided. Verbalizing these defences or confronting them is out of the question. The approach mediated by an artistic language is precisely a detour strategy, which allows to circumvent these defences at first. All defence mechanisms are designed to secure the ego and to save it from experiencing unpleasure, from within and from the outside world. The defensive measures of the ego, against the id are carried put invisibly. Anna Freud [9] lists nine defenses previously described in the literature - regression, repression, reaction formation, isolation, undoing, projection, introjection, turning against the self, and reversal. To these nine, she adds sublimation. These ten are the defenses available to the ego in its conflicts with the instinctual representatives and their affects.

In a discussion of art therapy within a psychoanalytic framework, it is necessary to address the concepts of symbolic function and symbolization, as they have shaped the way we approach art therapy in children. Vygotsky was a dominant figure in the study of language and the way it connected to symbolic function and symbolization in children. For Vygotsky, language is a mental tool that allows individuals to develop mental processes such as thought, perception and memory, while it functions as a symbolic mediator connecting intrapsychic functions to environmental stimuli [10]. This mechanism, called symbolization, was defined as a psychic apparatus, which allows individuals to exchange meaning between the inner and external reality, between the past and the present and the subject and object. Vygotsky acknowledged three stages of symbolization; during the first stage the child's activities are transformed through the exchange between the subject and the reality and reappear as an internal mental schema. During the second stage, the child's interpersonal relationships are transformed to internal mental schemas stored in the child's psyche, and lastly at the last stage, which requires the development of language as a mediator, the child uses a mental representation process in order to create transformations that allow them to make sense of their experience and environment [10]. The process of representation is achieved through mentalization, or "reflective mode," when mental states are experienced as representations. Mentalization "comes about the child's experience of his mental states being reflected on, prototypically through experience of secure play with a parent or older child, which facilitates integration of the pretend and the psychic equivalence modes, through an interpersonal process that is perhaps an elaboration of the complex mirroring of the infant by the caregiver" [11]. Another theorist who emphasized the importance of representation and symbolic function for children was psychoanalyst Anzieu, who connected transitional space and symbolization; he theorized that a child's ability to symbolize and use mental representations to make sense of their surroundings is rooted in an embodied experience of the self, where mind and body are not separate as in the western schools of thought [15]. According to these approaches, art therapy and pretend play can function as a transitional space where the child can freely process internal psychic material and express it through the use of art equipment, resulting in the resolution of internal conflicts and traumas.

In the present research, the aforementioned concepts are incorporated in the process of theatrical play, as theatrical play is defined as a process including two indispensable and complementary dimensions: Firstly, it is about theater, that is, about representing reality, a reality that comes to life through the use of dramatization. This is why theatrical play is freer and more personal, without predistributed roles, pre-defined words and pre-set scripts that have to be followed. Secondly, it is about playing, that is, 
about free expression that brings joy and entertainment to the participants. Theatrical play is nothing more than a form of pretend play, that is, a play that requires the representation of experience and external (everyday life) or internal (fantasies) reality through mental representations of experiences brought in action through the mechanism of deferred imitation. During theatrical play the participant-actor engages to what Piaget names "symbolic play", a play of make-believe and "as if". Symbolic play introduces the world of mental representations and symbols, the world of the signified, in the sense that the participants dramatize their past experiences in a process of actualization that satisfies the ego rather than subordinating it to reality, and of the signifiers, in the sense that those representations, experiences and feelings are expressed my means of a dynamic, individual language [12]. Piaget considers symbolic play to be a milestone in children's development, as it constitutes a principal expression of an established system of symbolic function, which serves as the quintessence for the development and sustainability of the sense of oneself, as well as the distinction of oneself from others [12]. In this direction, theatrical play, as a form of symbolic play, require limits: that is, a delimitation of space, time, context, a delimitation between oneself and the Other but also a delimitation of rules set by co-players as well as by play itself.

Theatrical play favors the development and establishment of symbolic function through the following processes. The creation of a reality based on mental representations of experiences, events, imagination, imagery and fantasies, in other words, what Piaget [13] called the "semiotic function". That is, the creation of a self (role, character of the play) that simultaneously exists and does not exist, in a reality (scenery, plot, story) that simultaneously exists and does not exist. During theatrical play, objects, body, language, even oneself, acquire characteristics that may have never possessed in reality, as the latter is transubstantiated, altered, or even created with mental material. Thus, theatrical play requires but also cultivates the formulation of mental symbols through a dialectical process with physical reality, favoring the indexical mode of the symbolic function. In this world of dramatization where reality and un-reality co-exist, the child participates in what Winnicott describes as the "creation of an illusion" [8].

The story that is dramatized through theatrical play has a beginning, middle and an ending as well as a context within which it unravels. This organization of the story in a spatio-temporal and logical sequence serves as a ground for the establishment of the iconic experience, that is, the ability to form mental experiences created by a flow of mental images, later crystallized as the child's "personal narrative" through the process of actualization. Thus, through the narration of the dramatized story, the child becomes capable of forming his personal narrations, the material for the creation of a sense of self.

Theatrical play serves as a process of delimitation: theatrical play takes place within limited space and time, thus offering the participants consistent spatio-temporal points. Further, as participants engage in roles-characters, they learn how to discern ego from non-ego. During theatrical play, the participant-actor "wears a mask without confusing himself with the mask" [14]. Through this dimension of theatrical play, the participant sets the limits between himself and others, recognizing his body image and using it as a means to express, dramatize and set consistent referral points in space, time and reality. It is this arbitrary boundary between existence and non-existence that finally sets the limits between reality and non-reality, creating consistent spatiotemporal points deriving from the realization of body image.

Within this frame of limits, in the form of self, space, time and structure of the dramatized story, a safe place where participants' fantasies can be expressed is created. An in-between space is thus developed, a space that is "neither a matter of inner psychic reality, nor a matter of external reality" [14]. The place and time of the dramatization as well as the story with its structured sequence itself becomes a transitional space where children's negative and positive feelings are expressed but also protected from the external world. In that sense, theatrical play serves the function of a container (contenant) of children fantasies, corresponding to what Anzieu would describe as the skin-ego (moi-peau) [15].

The aim of this research is to use theatrical play as a way of developing the symbolic function of children with anxiety symptoms, with the ultimate goal of alleviating the anxiety symptoms and improve their emotional wellbeing. More specifically, the hypotheses of this research are that three children, aged 10-12, with anxiety symptoms will be able, by the end of the theatrical play sessions, to:

a. Acquire a more complex form of symbolic play using their mental representations in order to reform or even create reality, as an external expression of a more processed and developed indexical mode of symbolic function.

b. Restructure reality using sequential representations in terms of space, time and relationships between causes and consequences, as an external expression of a more processed and developed logicomathematical reasoning ability, that will in turn lead to the emergence of personal narrative based on the iconic mode of the symbolic function, thus a continuity in the sense of oneself.

c. Process their body schema and use it to represent a consistent referral point in space and time, as an observable expression of the differentiation between ego and non-ego (role) and the delimitation between internal and external reality as well as between self and Other, that emerges from the maturation and development of the symbolic function.

$\mathrm{d}$, Be able, through the development of symbolization, to stand in a typical classroom alongside their peers with typical development, being included both academically and socially.

In other words, the hypothesis in the present article refers to the effectiveness of twelve sessions of theatrical play orchestrated by the researcher in the reduction of anxiety symptoms for three children aged 10 to 12 years old.

\section{Methods}

\subsection{Participants}

In this case study the sample consisted of three 10 to 12 years old children, a boy and two girls, who were referred 
to our practice for anxiety symptoms. In order to use a definition of anxiety that is shared and understood among mental health professionals on an international level, we have adopted the term as defined by DSM-5 when discussing anxiety related conditions. In detail, anxiety is defined as 'the presence of excessive [anxiety and] worry about a variety of topics, events, or activities... The worry is experienced as very challenging to control... The anxiety and worry are associated with at least three of the following physical or cognitive symptoms: edginess or restlessness, tiring easily; more fatigued than usual, impaired concentration or feeling as though the mind goes blank, irritability (which may or may not be observable to others), increased muscle aches or soreness, difficulty sleeping (due to trouble falling asleep or staying asleep, restlessness at night, or unsatisfying sleep)' [16]. In our research, children visited our office with their parents due to an abrupt change in their behaviour. A conversation with the parents revealed that many parental conflicts had preceded the change in children's behaviour. In fact, accumulating evidence indicates that family/parenting behaviours are associated with the etiology of anxiety disorders in children. Bögels and Brechman-Toussaintthis [17] reviewed different clusters of family variables associated with anxious symptomatology and anxiety disorders in children. One of them was the broader family factors, such as the relationship between parents. There is little doubt that parental conflict has negative consequences for children. Children's symptoms of anxiety could be explained through parental aggression towards each other during the conflict. In a longitudinal study conducted by Mechanic and Hansell [18], adolescent-reported family conflict (which included parental, sibling, and parent-child conflict) was associated with increased adolescent anxiety over time. Thus, parental conflict serves as a general stressor to a child's environment, threatening the child's sense of security.

The first girl, here named Anna for reasons of confidentiality, was a single child who had been experiencing loss of sleep, loss of concentration in school and irritability for the past three months according to its mother. The second girl, named Isabella, single child as well, belonged to a single parent family and suffered from loss of concentration within the classroom and excessive fatigue according to her mother. The boy, named Eric, brother to two younger sisters, had suffered a sudden drop of grades in school and demonstrated edgy behaviour and restlessness, according to his parents.

All children had undergone medical tests in order to exclude medical reasons for their symptomatology. The children were referred approximately the same time period and it was deemed appropriate to create a therapy group and employ drama therapy techniques for a 6 months period in order to alleviate the symptoms. The parents consented to that and it was agreed that meetings would take place in the properly-equipped playroom of the practice every two weeks. Before the beginning of the theatrical play sessions, two projective tests, Kinetic Family Drawing [25] and Draw-A-Person [24], were employed in order to explore the emotional stability of the participants and identify the anxiety symptoms as they influence their emotional well-being.

\subsection{Materials}

In the field of psychology, projective techniques have defined most assessments of children. Their application is aimed at measuring unconsciously repressed thoughts and feelings, and they have allowed for a deeper understanding of unconscious material [19]. Psychoanalysts have used projective drawing techniques to investigate further emotional and social dysfunctions of children and adolescents from a holistic, interpretative perspective $[20,21,22,23]$. Among the most popular projective techniques are the Draw-A-Person (D-A-P) [24], and the Kinetic Family Drawing (KFD) [25].

The first projective drawing technique used here, which is commonly used with children is the Kinetic Family Drawing (KFD) [25], which was designed to assess children's perceptions of the relations among their family members. Since the introduction of the KFD in the field, it has been employed widely among psychologists who work with children because it addresses the importance of family dynamics in the etiology and treatment of emotional disorders of children [26]. In the KFD, children are asked to draw a picture of their family doing something, as its creators suggested that having children do something would allow self and family attitudes to become more apparent. Two manuals for scoring the KFD have been developed. Their system is based on the interpretation of actions, styles, and symbols in the drawings. Their method, however, has been harshly criticized because their manuals include no information on reliability or validity and fail to define precisely the scoring variables [22]. Studies specifically investigating the KFDs of depressed and anxious children, regardless of the scoring system used have been reported, and show that anxious children tend to score differently than children who show no symptoms of anxiety.

Regarding the D-A-P, its administration typically involves the completion of three different drawings on three pieces of paper, which takes place upon request by the researcher. It is usually asked of children to draw a picture of a man, a woman, and themselves [24]. The administrator does not provide any further instructions and does not answer children's specific questions in case they have any. Additionally, there is no time limit to the completion of the test, but it is common for children to spend ten to fifteen minutes in order to finish. Due to the test being non-invasive and non-threatening to children, it is widely used by researchers. In this research the D-A-P is administered partly; children are only required to draw one figure, that of themselves [24]. This was decided as the D-A-P was administered after the KFD, which includes the drawing of the child's family; requesting children to draw similar figures and themes twice would risk repetition.

Furthermore, the materials used during the theatrical play consisted of the equipment available in the playroom of the researcher; pieces of clothing in different colours, toys such as dolls of both genders, stuffed animals, toys that represented items of everyday life such as kitchen appliances.

\subsection{Procedure}

The initial meeting, which took place into our offices, consisted of the completion of the above tests, D-A-P and 
KFD, which measured the emotional well-being and anxiety symptoms of the children. Each child completed the test in private with the researcher and the results are presented in following sections. The employment of the tests was completed within one session, and the next session that followed was introductory to the theatrical play.

The formal process of employing the KFD was followed: the children were given the instructions '-Draw your family. You can draw it however you want, but remember they have to be doing something', and a piece of A4 paper as well as a pencil. After the completion of the KFD, the children were given the D-A-P test, which was also completed on a piece of A4 paper using a pencil.

Following the completion of the projective tests, children were introduced to the theatrical play in the next session.

Each theatrical play session consisted of four stages:

Phase one: The preparation - the children were introduced into the playroom and were prepared by the researcher to enter the process through body exercises, movement games, and the use of sensorimotor action [27].

Phase two: The reproduction - during this phase the researcher provided the children with a stimulus and they responded to it by discovering and developing their role within the play in accordance to that stimulus. The stimulus could be an object related to the play, such as a piece of clothing or a puppet, a sound, such as a song or melody that the children had associated with a popular fairy tale, or an image, that could represent anything related to the content of the play.
Phase three: the scenic improvisation - theatrical performance: during this phase children chose the role that they wished to perform, from a group of roles made available by the researcher and determine the content and nature of their story.

Phase four: Analysis, discussion, processing: this phase concerns the processing of everything that took place. The team discussed any concerns which might have arisen during the previous stages and expressed their feelings and thoughts through music, drawings and narrative.

A more detailed description of the methodology is depicted in Table 1.

For better understanding of the ongoing process of children's skills and abilities, we present firstly, the initial theatrical play sessions, and secondly, we compare the first and last theatrical play session. It should be noted that our analysis is based on observations taken by the researcher throughout the process.

The observation of the first theatrical play sessions revealed that:

Children were first reluctant to engage in group activities as it was the first time they met each other and the intimacy required by the procedure seemed unfamiliar to them. Thus, the first session felt 'clumsy', as they characterized it, and 'awkward'; this was obvious through their bodily movements, which for the most part were uncoordinated. Besides this, when adopting roles in the theatrical play they seemed to be greatly dependent on the researcher and did not take initiative at any point during the performance.

Table 1. Methodology Stages

\begin{tabular}{|c|c|c|c|}
\hline Description of stage & $1^{\text {st }}$ stage & $2^{\text {nd }}$ stage & $3^{\text {rd }}$ stage \\
\hline Design & Children draw themselves & $\begin{array}{l}\text { Planning of activities for body-image } \\
\text { retraining }\end{array}$ & $\begin{array}{l}\text { Exercises for body knowledge and somatic } \\
\text { expression. Enrichment with stimuli of } \\
\text { progressive complexity for activation. }\end{array}$ \\
\hline Action & $\begin{array}{l}\text { Children design the theatrical } \\
\text { space }\end{array}$ & $\begin{array}{l}\text { The activities take place during the } \\
\text { theatrical play sessions. }\end{array}$ & $\begin{array}{l}\text { Implementation of activities and theatrical } \\
\text { play sessions with less direction from the } \\
\text { researcher and greater opportunities for } \\
\text { improvisation for the children }\end{array}$ \\
\hline Observation & $\begin{array}{l}\text { Children's drawings } \\
\text { interpretation }\end{array}$ & $\begin{array}{l}\text { Note taking of theatrical play } \\
\text { sessions. Discussion on the session } \\
\text { by the team (researcher, children) }\end{array}$ & Taking notes, comments \\
\hline Critical thinking & $\begin{array}{l}\text { Children draw themselves, parts } \\
\text { of the performance and } \\
\text { characters of the theatrical play }\end{array}$ & $\begin{array}{l}\text { Action is still poor. Motion, on the } \\
\text { other hand, seems self-controlled (by } \\
\text { the subject), as well as controlled by } \\
\text { others (the team dynamics) }\end{array}$ & $\begin{array}{l}\text { During the last theatrical play sessions, } \\
\text { children cooperate, create stories and act } \\
\text { without the intervention of the researcher. }\end{array}$ \\
\hline
\end{tabular}

Table 2. Comparison between first and last session

\begin{tabular}{|l|l|l|}
\hline & First session & Last session \\
\hline Movement & $\begin{array}{l}\text { Many movement games, in order to: } \\
\text { Physically prepare children for the action of the } \\
\text { following phases, } \\
\text { Observe the way they move in space } \\
\text { Discover problems in the level of 'body and space' }\end{array}$ & $\begin{array}{l}\text { No movement games, as children entered, without any special } \\
\text { preparation, the main subject of play (building a house hospital) }\end{array}$ \\
\hline Use of materials & $\begin{array}{l}\text { Children were given a piece of fabric and were asked } \\
\text { to move in space and create a story with it. No other } \\
\text { material was used spontaneously by them. }\end{array}$ & $\begin{array}{l}\text { Children spontaneously used pieces of fabric, desks and yoga mats } \\
\text { in order to 'build' a 'house'. They used papers, colours, boxes, } \\
\text { rulers, newspapers. }\end{array}$ \\
\hline $\begin{array}{l}\text { Creation of an } \\
\text { environment of action }\end{array}$ & $\begin{array}{l}\text { A piece of fabric in the middle of the circle served as } \\
\text { an imaginary mat that transferred them to the location } \\
\text { where all action took place. }\end{array}$ & $\begin{array}{l}\text { In the middle of the playroom, children constructed a scenery, where } \\
\text { they were able to take on the roles they had developed in earlier } \\
\text { sessions and act out dramas created in previous sessions. }\end{array}$ \\
\hline Dressing up & Children used the table cloth as a bed. & $\begin{array}{l}\text { Children wore on their heads paper hats and created masks out of } \\
\text { newspaper to act out their chosen roles. }\end{array}$ \\
\hline $\begin{array}{l}\text { Performance within a } \\
\text { scenery. }\end{array}$ & The piece of fabric represented the ground. & $\begin{array}{l}\text { Children 'built' a house for their characters. The researcher asked of } \\
\text { the role the house has in their story and the children expressed the } \\
\text { concept of continuity and picked up from where they had left the } \\
\text { previous session. }\end{array}$ \\
\hline
\end{tabular}


Comparing the first and last theatrical play sessions, we observed the following:

During the first session, many activities and games were used in order to develop accurate profiles concerning children's orientation in space and time, and to progressively introduce them to the activities of the following theatrical play phases. During the last theatrical play session, an increase in children's interest for space and activities was observed, as well as a deeper understanding of the symbolic codes of communication (roles, clothing, participation, rhythm)

a. During the first session, children used the material of the playroom only after the intervention of the researcher. During the last session, children enthusiastically built their toys, scenery and clothing all by themselves.

b. During the first session, children seemed uncomfortable, did not know how to use the scenery and were unable to create a story in order to initiate play. During the last session, children created the scenery by themselves and actively participated during the play, without the direct intervention of the researcher.

\subsection{Projective Tests}

\subsubsection{Anna}

Anna, a 10 years old girl experiencing loss of sleep, lack of concentration in school and irritability, demonstrated signs of change between her first and second testing phase, both in the content and the verbal and nonverbal behaviour during the testing process.

\section{Phase one}

In detail, the first time she completed the KFD, her drawing style was consistent with anxiety symptomatology in children, as she drew little figures, devoid of expressions, using simple lines and her style appeared to be indecisive. Moreover, she drew herself within a house, which is a sign of her need for protection and withdrawal of the outside world. The drawing can be considered small, as it occupies less than half of the sheet. small drawings are generally related to anxious and insecure attitude; this is consistent with her behaviour at home and at school. Furthermore, the figures drawn are located on the central part of the sheet. She mostly drew in the middle of the paper and tended to move to the lower right. This progressive movement to the right could be indicative of anxiety during the task, which is reinforced by other characteristics of her drawing: inclination, deletions and drawing over the lines. In terms of the D-A-P, Anna drew lines in an undecisive manner, without clearly marked lines and a tendency to gap and overlap. The lines lacked consistent joining, and the outline of the head had obvious irregularities. These could be interpreted as signs of insecurity and anxiety. Finally, during the completion of both tests she kept asking directional questions constantly and was looking around, also signs of anxiety and lack of confidence.

\section{Phase two}

After the completion of the theatrical play sessions, Anna completed the same tests and produced different results. In the KFD test, her drawing was more symmetrical and the lines seemed wavy and more defined, which is a sign of control of the self and more positive self-image. This is also apparent in the good organization of the space, as the size of the drawing was more proportional to the sheet and the figures more in line with each other in terms of size. Besides this, the size of the figures seemed more proportional compared to the first test she completed. Additionally, the faces had more clearly defined expressions, and these expressions were positive. Nevertheless, the arms were stuck to the body, and the head was tilting to the right, which usually signify dysfunctional social relations. In this case, her non-verbal behaviour showed more confidence, which could be attributed to the fact that the space and the researcher were now familiar to her.

\subsubsection{Isabella}

Isabella, a single child of 10 years old, belonging to a single parent family and came to us because she experienced loss of concentration in the classroom and excessive fatigue according to her mother.

\section{Phase one}

When Isabella first came in for the completion of the KFD, she was not keen to separate from her mother, but seemed comfortable when sitting at the table with the researcher and the paper and colours. Her drawing presented typical signs of insecurity, as the arms and legs were drawn disproportionally small to the rest of the body, and the arms were stuck to the body, whereas the legs were too thin. Besides this, the figures were drawn with a worth noticing distance from one and other, which indicates her difficulty in relating to her immediate environment. Her behaviour while drawing was typical of an obsessive personality, as she kept using similar colours when painting and when kept erasing in order to paint over her figures. Upon erasing a 'mistake', as she called it, she proceeded to erase completely the drawing in an obsessive way that was characteristic of an obsessive personality. Research shows that erasures are not common among children, so when they appear express difficulties in emotional expression.

When completing the D-A-P test, Isabella did not proceed to erase as much, but exerted conscious control over the drawing and was very careful to stay within the lines. In line with her behaviour when completing the KFD, this tendency for perfectionism is typical of an anxious, obsessive personality. In addition, the details of the limbs were inconsistent, as the number of fingers was different on each hand, while the shading was subtler in the core than on the face; the face seemed to be covered by a darker shade, clear sign of distress.

\section{Phase two}

The second time Isabella completed the KFD, the obsessive behaviour demonstrated in the first session was still present, as she exhibited the same tendency to erase and start over. Nonetheless, the difference in the figures drawn was distinct; they were now standing closer to each other and their arms were extending towards one and other, as if trying to physically connect. Moreover, the lining of 
the figures was more defined, and the content of the drawing was different as well. In detail, in the first drawing Isabella had included a mother and a child (herself), and the child was positioned on the left side of the sheet while the mother was in the middle, poorly drawn. Here, the child was positioned in the middle next to the mother, and the shading was less prevalent compared to the first drawing.

In regards to the D-A-P, the second testing also produced mixed results; Isabella kept to over shading her drawing and she exhibited signs of anxiety, as she was biting her pencil and asking questions during the process, even though it was the second time she did this. However, the lines of her drawing were more defined, and she withdrew from shadowing the figures excessively. Thus, it can be argued that part of the anxiety which was evident in her first attempt was no longer present in the content of the second testing.

\subsubsection{Eric}

\section{Phase One}

Eric, a 12 years old boy with a sudden change of performance in school and behaviour characterized by his family and teachers as 'edgy and provocative', was cooperative during the completion of the KFD, yet he seemed to lack confidence as he kept asking the researcher; 'am I doing it right?', 'what should I do here?', 'I'm not sure how to go on', clear signs of anxiety when faced with a unfamiliar situation. In terms of the content of his drawing, he drew a picture of his family in which he and his sisters were inside a house, while his parents were positioned outside the house, looking away from the house. The different positioning of the family members portrays a sense of abandonment on behalf of Eric, and the fact that he positioned himself inside the house shows his need of protection. Additionally, he drew himself with an expressionless face, whereas his family was smiling, sign of distress.

In the D-A-P drawing, Eric struggled to draw a figure, as he proceeded in uncontrollable scribbling for a while and then ended up drawing a figure with relatively clear lines and distinct characteristics.

\section{Phase Two}

Upon completion of the theatrical play sessions, Eric returned for the completion of the tests and exhibited a different behaviour as he seemed more confident and asked less questions during the KFD. As mentioned above, this could be a product of his being familiar with the space and the researcher. In this case, the drawing of the family was different as well; he positioned the whole family outside the house, holding hands and smiling. Eric's case was the one with the most worth-mentioning results, as the swift in the positions of the family members in his second KFD was characteristic of emotional growth and a resolution of intra family tension, as in the first KFD the family was separated and portrayed akinetic, whereas in the second testing the holding of hands indicated movement; research has shown that this change in a child's drawing style suggests a healthier dynamic among family members and an improved communication of emotions. Apart from that, the fact that in the second drawing the whole family was placed outside the suggests that Eric no longer feels threatened and in need of protection.

Regarding the D-A-P, the second time Eric proceeded in drawing a figure with similar characteristics as the first D-A-P he completed, however in this case there was minimal scribbling. Indeed, he drew confidently a figure with clear lines and positioned it in the middle of the sheet, and all the limbs of the figure were proportional and symmetrical, showing greater emotional stability compared to the first time.

\section{Discussion}

Evaluating the observations we obtained from the theatrical play sessions, we concluded that:

a. Theatrical play was a favourable mediating tool for the improvement of the emotional functioning of neurotypical children with symptoms of anxiety, as it is a spontaneous activity without restraints, during which children express themselves as they want or as they can, without being submerged to direct or indirect critique by his team of reference.

b. Theatrical play favoured the improvement of children's communication skills, their autonomy, and the progressive development of abstract thinking and metacognitive skills such as:

c. The detailed description of a story by means of movement in space

d. Movement efficiency and effectiveness, with the latter referring to 'thought' (I play what I think of)

e. Originality in presentation, as each child develops a different story to express their thoughts.

f. Theatrical play favoured the transition from literal to figurative language and symbolic meaning of words. All the activities performed during the theatrical play aimed in enabling the participating children to understand the elementary structures of oral language through symbolic expression, expression of feelings, rhythm and imaginary representations of the reality of play. In this way we observed that through our psychopaedagogic intervention, children with symptoms of anxiety were able to experience, understand and perceive the psychosomatic frame, in which the characters of each story or fairy tale act.

g. The psychopaedagogic intervention was effective mostly through the implementation of psychomotor education, which aimed in helping children with symptoms of anxiety as the body was the major contenant for the expression of the contents of their thoughts (narcissistic, archaic and symbolic contents).

h. Given the fact that anxiety obstructs symbolic functioning, we hypothesized that therapeutic sessions using theatrical play and symbolic imitation, which is one of the most important forms of symbolic function, children experience, perceive, decode and understand the symbolic and psychic frame, in which the action of the characters of each story or fairy tale takes place. Thus, through the processing of the symbolic function, children learn 
to connect their personal wishes with their role during play, to conform to the roles of the theatrical play, to represent the actions of the character by means of movement, thus being able to construct an imaginary representation of reality and being able to place themselves in a 'transitional place' and amidst 'transitional phenomena' [28].

i. The content of the theatrical play activities that were used in our analysis favoured - through dramatization- the emotional reconstruction of cognitive functions concerning the emotional field of self and hetero - reference, that is, the establishment of communication within the team. It becomes clear that theatrical play favoured the progressive development of the symbolic function, as during the pre-operational and concrete stage of intelligence [13], symbolic play optimizes the ability to discern Ego from non-Ego (role) [29,30]. Further, symbolic play prepared children to perform their roles, given the fact that 'pretending means that I can cover myself with a mask, without confusing myself with the mask' [14].

j. The transition from one phase of theatrical play to another was followed by many regressions from the children's part. However, those phases were an ongoing feedback and motivation for the successful transition from one phase to another. More specifically, in every dramatization phase, children performed different roles. This way, we ensured that children performed all roles, so that children would determine the choice of the role themselves, thus becoming emotionally involved in the interaction with their teacher, peers, but also the team dynamics.

In terms of the effect of theatrical play to children's emotional well-being and anxiety levels, it is evident from the projective tests used before and after the theatrical play sessions that theatrical play had a mediating effect on children's anxiety levels. The interpretation of the KFD and the D-A-P described here allows for an understanding of the emotional state of the children before and after the completion of the sessions.

\section{Conclusion}

As a conclusion, we should note that, according to the psychoanalytic theory $[31,32,33,34]$, children in the latent stage of psychosocial development are trying to construct their Ego, as well as an Object. Therefore, we assume that theatrical play worked as an aid to the children's Ego; that is, it favoured the installation of the symbolic process as a mediator for the construction of the real and specific. In detail, through symbolization, children were enabled to activate a system of intra- and intersubjective exchanges. This process is in line with analytic therapy, which, in the standard model, assumes a relation between two centers of meaning, the analyst and the patient, whose work is possible only on condition that it is referred to an outside agency, which is the "frame" of analysis [36,37].

This successful installation was supported by a variety of motives offered by the principles of theatrical play, as well as by the role of the researcher who functioned as an aid of children's Ego and supported their self-esteem [30].
The above psychological process clearly aided in the reduction of anxiety symptoms, as portrayed in the projective tests that took place at the end of the theatrical play sessions. The repetition and symbolic imitation of the story context helped the children to assimilate a variety of learning experiences. This way, in every new session children showed improvement in generalizing the skills they had acquired as well as the ability to transfer them in new situations through improvisation. This transferability allowed children to mentally represent the characters' actions, and to update them if necessary during an upcoming performance, thus acquiring what Piaget [12] referred to as differential imitation. In reference to the symbolic function, which seemed to be activated during the stages of theatrical play, our findings are in accordance to the work of previous researchers, such as Mayes and Cohen [35]. They approached the subject from a developmental and psychoanalytic perspective and demonstrated how children create their inner reality when interacting with their parents in an early age, through the means of internalization [38].

\section{References}

[1] Boucher, J. (1999). Pretend play as improvisation: Conversation in the preschool classroom. British Journal of Developmental Psychology, 17, 164-165.

[2] Corey, G. (1996). Theory and practice of counseling and psychotherapy. Pacific Grove, CA: Brooks/Cole.

[3] Klein, M. (1964). Contributions to psychoanalysis. New York: McGraw-Hill.

[4] Robbins, A. (1987). The artist as therapist. New York: Human Sciences Press.

[5] Robbins, A. (2001). Object relations and art therapy. In J. Rubin (Ed.), Approaches to art therapy (2nd ed., pp. 54-65). New York: Brunner-Routledge.

[6] Henley, D. (1991). Facilitating the development of object relations through the use of clay in art therapy. American Journal of Art Therapy, 29, 69-76.

[7] Henley, D. (1992). Exceptional children, exceptional art. Worcester, MA: Davis. Jacobi, J. (1942). The psychology of C. G. Jung. London: Routledge \& Kegan Paul.

[8] Winnicott, D. (1953). Transitional objects and transitional phenomena. International Journal of Psychiatry, 34, 89-97.

[9] Anna Freud Austrian-British psychoanalyst. Encyclopædia Britannica. Retrieved 2017-04-15.

[10] Vygotsky, L. S. (1967). Play and its role in the mental development of the child. Soviet psychology, 5(3), 6-18.

[11] Fonagy, P., Steele, M., Steele, H., Moran, G. S., \& Higgitt, A. C. (1991). The capacity for understanding mental states: The reflective self in parent and child and its significance for security of attachment. Infant mental health journal, 12(3), 201-218.

[12] Piaget, J. (1970). Piaget's theory.

[13] Piaget, J. (2013). Play, dreams and imitation in childhood (Vol. 25). Routledge.

[14] Winnicott, D. W. (1971). Therapeutic consultations in child psychiatry. New York: Basic Books.

[15] Anzieu, D. (2016). The skin-ego. Karnac Books.

[16] American Psychiatric Asssiation. (2013). Diagnostic and statistical manual of mental disorders ( $5^{\text {th }}$ edition). Washington, DC: Author.

[17] Bögels, Susan M., and Margaret L. Brechman-Toussaint. "Family issues in child anxiety: Attachment, family functioning, parental rearing and beliefs." Clinical psychology review 26.7 (2006): 834-856.

[18] Mechanic, D., \& Hansell, S. (1989). Divorce, family conflict, and adolescents' well-being. Journal of Health and Social Behavior, 30(1), 105-116.

[19] Meichenbaum, D. (1977). Cognitive behaviour modification. Cognitive Behaviour Therapy, 6(4), 185-192. 
[20] Lubin, B., Larsen, R. M., \& Matarazzo, J. D. (1984). Patterns of psychological test usage in the United States: 1935-1982. American Psychologist, 39(4), 451.

[21] Louttit, C. M., \& Browne, C. G. (1947). The use of psychometric instruments in psychological clinics. Journal of Consulting Psychology, 11(1), 49.

[22] Sundberg, N. D. (1961). The practice of psychological testing in clinical services in the United States. American Psychologist, $16(2), 79$.

[23] Wade, T. C., \& Baker, T. B. (1977). Opinions and use of psychological tests: A survey of clinical psychologists. American Psychologist, 32(10), 874.

[24] Saracho, O. N. (1984). The Goodenough-Harris Drawing Test as a measure of field-dependence/independence. Perceptual and motor skills, 59(3), 887-892.

[25] McPhee, J. P., \& Wegner, K. W. (1976). Kinetic-Family-Drawing styles and emotionally disturbed childhood behavior. Journal of Personality Assessment, 40(5), 487-491.

[26] Reynolds, C. R., \& Richmond, B. O. (1978). What I think and feel: A revised measure of chidren's manifest anxiety. Journal of abnormal child psychology, 6(2), 271-280.

[27] Hooper-Greenhill, E. (1991). Museum and gallery education. Leicester University Press.

[28] Winnicott, D. (1965). The maturation processes and the facilitating environment. New York: International Universities Press.
[29] Freud, S. (1905). Analysis of a phobia in a 5-year-old boy (Vol. 10). London: Hogarth Press. Freud, S. (1916-1917). Introductory letters on psychoanalysis (Vol. 12). London: Hogarth Press.

[30] Freud, S. (1918). From the history of an infantile neurosis (Vol. 17). London: Hogarth Press. Furth, G. (1988). The secret world of drawings. Boston: Sigo.

[31] Fonagy, P. (2018). Affect regulation, mentalization and the development of the self. Routledge.

[32] Pedder, J. R. (1979). Transitional space in psychotherapy and theatre. Psychology and Psychotherapy: Theory, Research and Practice, 52(4), 377-384.

[33] Summers, F. (1999). Psychoanalytic boundaries and transitional space. Psychoanalytic Psychology, 16(1), 3.

[34] Mayes, L. C., \& Cohen, D. J. (1992). The development of a capacity for imagination in early childhood. The Psychoanalytic Study of the Child, 47(1), 23-47.

[35] Mayes, L. C., \& Cohen, D. J. (1992). The development of a capacity for imagination in early childhood. The Psychoanalytic Study of the Child, 47(1), 23-47.

[36] Bion W. (1962), Learning from Experience, Londres, Heinemann; trad. fr. Aux sources de l'expérience, PUF, 1979.

[37] Bion, W. (1965), Transformations, Londres, Heinemann; trad. fr. Transformations. Passage de l'apprentissage à la croissance, Paris, PUF, 1982.

[38] Creme, P. (2008). A space for academic play: Student learning journals as transitional writing. Arts and Humanities in Higher Education, 7(1), 49-64. 